\title{
Analysis of the possibilities to achieve adiabatization process of combustion surrounded by inactive gases in Rapid Compression Machine
}

In this work non-combustible gases impact on combustion processes studies is performed. Research was performed in a optically accessible rapid compression machine (RCM) under spark ignition engine conditions. The distribution of the swirl charge in the relation to adopted for analysis sequence of gas delivery to the chamber was varied with regard to the main injection. Authors investigate the influence of these sequence on the combustion and the ignition delay of the main injection and the overall combustion characteristics. The aim of this work is the experimental recognition of possibilities of creating combustible mixtures of light hydrocarbon fuels surrounded by non-combustible gases affecting the function of the inhibitor. Specifying the ability of preparation and combustion of mixtures in such systems enables the scientific analysis of adiabatization of the combustion process of fuel-air mixtures in the operating chambers. Theoretical analysis of the issues indicates possibility of obtaining such a stratification of the charge, that the inactive exhaust gases creating the outer ring surround the combustible mixture inside in such a way as to reduce the amount of heat exchanged between the working medium and the walls of the cylinder.

Key words: exhaust gas recirculation, inactive gases, combustion fuels

\section{Introduction}

The selected problem of assessing the emergence and spread of flame is critical for the search of new opportunities to reduce toxic emissions in spark ignition internal combustion engines $[1,2,6]$. The proposed system is associated with a reduction in the energy indicators, however, due to the nature of the combustion and the advantage in the form of lack of heat loss in exchange with the cylinder walls, investigation of the subject is justified. In order to improve the efficiency of combustion engines the proper preparation of the combustible mixture in the cylinder chamber is very important. Suitable conditioning of the combustion process may allow a fuel consumption reduction. One of the methods that can be used to achieve those demands is to use recirculated exhaust gas in order to introduce a controlled volume of non-combustible gases into the cylinder $[6,9]$.

In contrast to the classic solutions currently used in engines, the arrangement shown involves supplying the nonflammable gases in a strictly defined manner. Paper [10] describes the possibilities of stratification of fuel load with non-combustible gases (separation of air and exhaust gas) which influenced the Authors to choose the described combustion system concept. Different options for such a stratification is shown in Fig. 1. Stratification can be divided into longitudal (from the left), axial, and radial. Radial stratification (Fig. 1c) of the air and exhaust gases is the most suitable choice, from the point of view of the compression stroke, in terms of maintaining the stratification during piston movement. The interior region of the fuel-air mixture is encased in the exhaust gas region. Both of these regions are coaxial in the cylinder, and therefore the compression stroke should not disturb the load stratification (the separation of injected air and exhaust gas). In addition, if the angular momenta of the loads are be kept during the compression stroke then a mass of air and exhaust gas swirling in the same direction will result in a much longer lasting stratification of the mixtures at the end of the compression stroke. a)

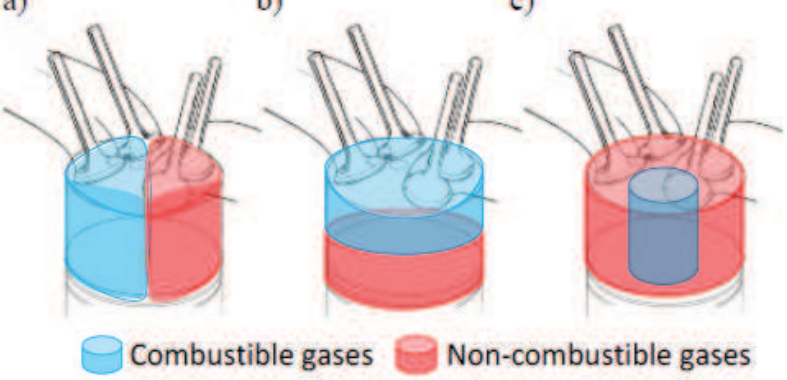

Fig. 1. Gases stratification modes: a) lateral, b) axial, c) radial [10]

The Authors performed simulations using the AVL Fire software preceding the experimental studies [5]. The results of these studies on different strategies to introduce gases into the combustion chamber were considered for possible initiation and control of the combustion process. In the analyzed cases, the aim was to achieve a strong wall guided flow, thus the calculations used the $\mathrm{k}-\xi$-f model developed by Hanjalica et al. [7]. The summary of the article is a choice of strategy of exhaust gas supply into the engine cylinder.

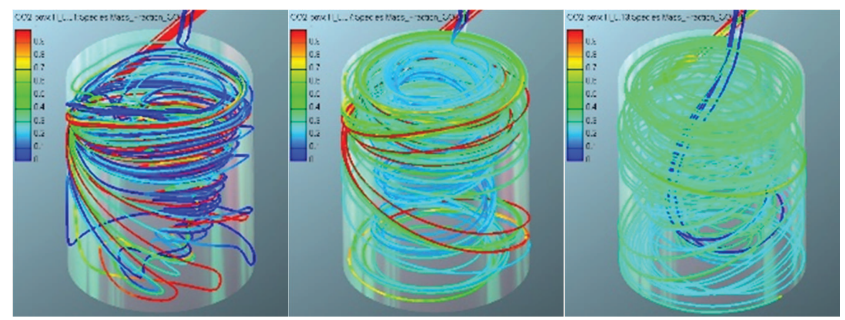

Fig. 2. Spatial distribution of the current lines during the sequence used in the study [5]

This article is a further research step taken by the Authors towards adapting the results of the simulation on a single cycle machine. 


\section{Research methodology}

The test stand with a Rapid Compression Machine imitates the working conditions of the internal combustion engine with spark ignition, direct injection, and has been adapted to the needs of this research. Test stand parameters are shown in Table 1.

Table 1. Characteristic of RCM [8]

\begin{tabular}{|l|c|}
\hline Quantity & Value \\
\hline Stroke & $89 \mathrm{~mm}$ \\
\hline Bore & $80 \mathrm{~mm}$ \\
\hline $\begin{array}{l}\text { Volume of combustion } \\
\text { chamber }\end{array}$ & $55 \mathrm{~cm}^{3}$ \\
\hline $\begin{array}{l}\text { Method of delivery } \\
\text { non-combustible gases }\end{array}$ & solenoid valves \\
\hline Compresion ratio & 11 \\
\hline $\begin{array}{l}\text { Type of combustion } \\
\text { chamber }\end{array}$ & $\begin{array}{c}\text { hemispherical chamber in the head + cham- } \\
\text { ber in the piston }\end{array}$ \\
\hline Optical access & $\begin{array}{c}\text { from the bottom of the combustion chamber, } \\
\text { quartz glass } \phi 50 \text { mm arranged in the piston }\end{array}$ \\
\hline
\end{tabular}

The adaptation of RCM, previously used by the Authors to study the dynamic [4] and optical processes, was to design an appropriate system implementing the injection of combustible and non-combustible gases into the combustion chamber (Fig. 3).

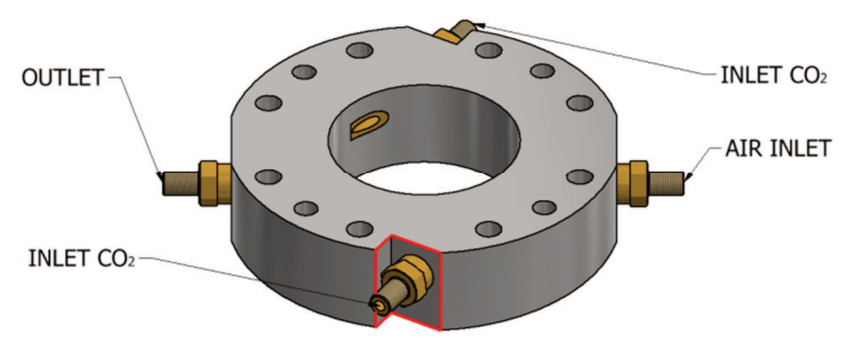

Fig. 3. Modified ring of RCM
The 3D model of the test stand with the elements necessary to carry out tests is shown in Fig. 4. In order to achieve a radial load stratification intake channels were added on the RCM periphery that fed non-combustible gases, controlled using solenoid valves, tangentially to the cylinder axis (13). Technical carbon dioxide was used as a noncombustible gas (9) with a purity of $99.95 \%$ by volume. The Rapid Compression Machine (8) operation is controlled using a sequencer $(1,2)$. An additional valve mounted in the head (12) is responsible for providing air in the spark plug area. In the first stage of the research presented in this article an outward-opening piezoelectric injector Siemens VDO (11) was located at the central point of the engine head. Spark plug (10) with the built in pressure sensor AVL GH13Z-31 is arranged in such a way that the formation and ignition of loads in RCM were carried out based on the spray guided combustion principle.

The elements used to perform tests on the present stand is:

- the high-speed camera (6) by LaVision, taking pictures with frequency of $5 \mathrm{kHz}$,

- piston displacement sensor - contactless potentiometric displacement sensor - Megatron LSR 150 ST R5k,

- the system for acquisition of measurements of fastvarying signals AVL IndiModul (4).

The obtained results: indicated (3) and optically measured (5) were processed using the following programs: AVL Concerto V4.5 and DaVis 7.2. The test results were compared with each other in relation to the recorded time.

\section{Thermodynamic indexes of combustion process}

A preliminary analysis of the impact of non-combustible gas injection into the combustion chamber is made on the basis of the indicated pressure registered in the combustion chamber. The system response has been shown in the form of the combustion process delay and a reduced increase of the maximum combustion pressure (Fig. 5).

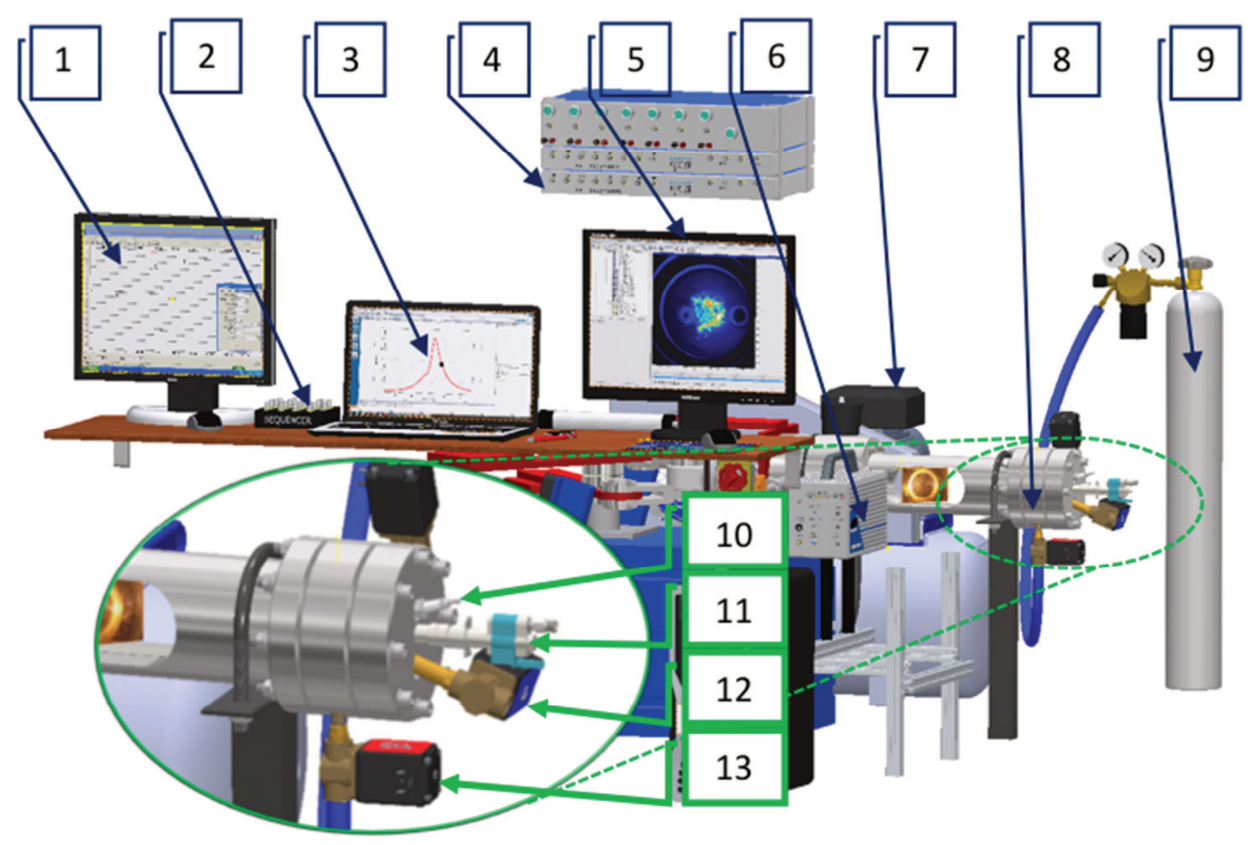

Fig. 4. Three-dimensional view of the measurement stand of Rapid Compression Machine 


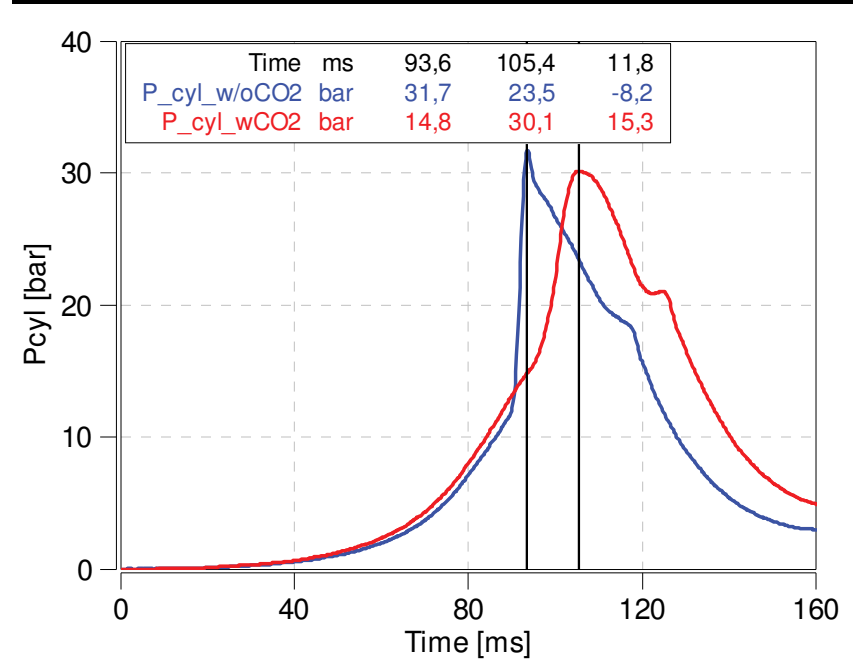

Fig. 5. The results of the measurements of the combustion pressure

In the arrangement without providing a non-combustible gas into the chamber, which serves as reference in studies, the maximum combustion pressure of 31.5 bar was acquired occurring within $93.6 \mathrm{~ms}$ after the piston movement began. Providing non-flammable gases into the combustion chamber in a selected sequence resulted in a delay of pressure increase of $11.8 \mathrm{~ms}$ and a reduction in the maximum pressure. Because of the previously cited articles, which demonstrated both the repeatability of RCM operation in the analysis of indicated parameters [4] and optical processes [3], the analysis covers two representative runs in which one is a reference run, and the second shows the effect of the proposed modifications. Figure 6 shows the heat release rate.

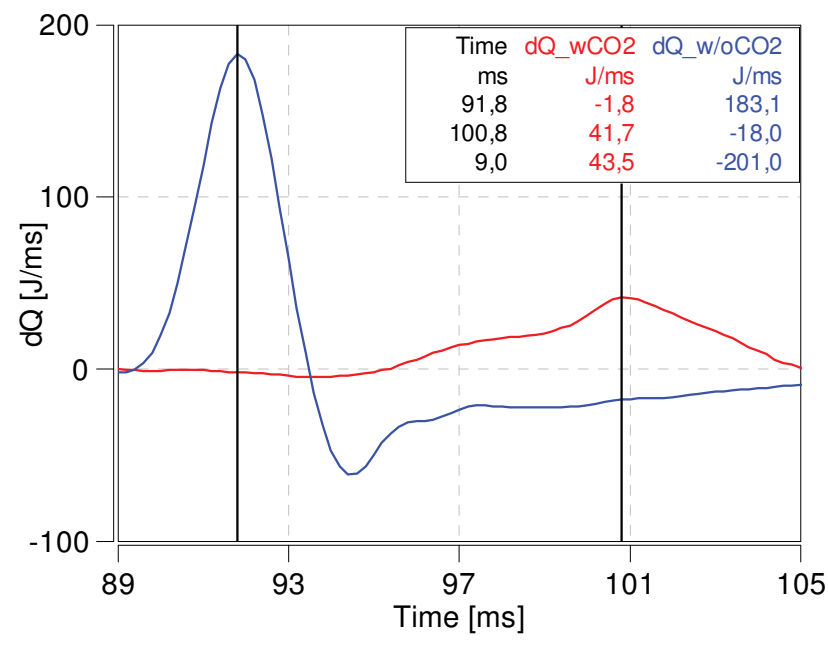

Fig. 6. Heat release rate

In this context, the fuel injection and combustion without the presence of non-combustible gases results in a large heat release rate with a maximum value of $183 \mathrm{~J} / \mathrm{ms}$. Using the load with recirculated exhaust gases strategy causes the combustion to be delayed significantly resulting in a far lower rate of heat release. Its maximum value is $41 \mathrm{~J} / \mathrm{ms}$, which is only $22 \%$ of the reference value.

\section{Optical analysis of the combustion process}

Optical test consisted of visual recording the combustion process in the RCM with a frequency of $5 \mathrm{kHz}$. In order to specify the area the flame takes up during combustion in a given system the recorded data was subject to digital processing consisting of: (1) defining the viewing window area mask and (2) counting the pixels whose radiation intensity was higher than the background noise. Then, by registering the triggered discharge on the spark plug, it was possible to determine a common time baseline for the indicator and optical research results (synchronization). Figure 7 shows the areas occupied by the flame in subsequent measurement attempts. Three functions relate to the classic combustion system without a supply of noncombustible gases and are marked in the article with the color blue, while the measurements using the supply system with non-combustible gases have been marked in red. The results of the calculated areas occupied by the flame have been again juxtaposed with pressure changes in the chamber. The results thus illustrate a direct correlation between the recorded test results of indicated pressure and the optical two-dimensional (flat) recording of the flame.

The reference measurements recorded a sharp flame size increase in the chamber, covering on average almost $100 \%$ of the viewing window located in the RCM piston. In this configuration, the flame is maintained for a long time in the whole viewing window, which indicates the long post-combustion process.

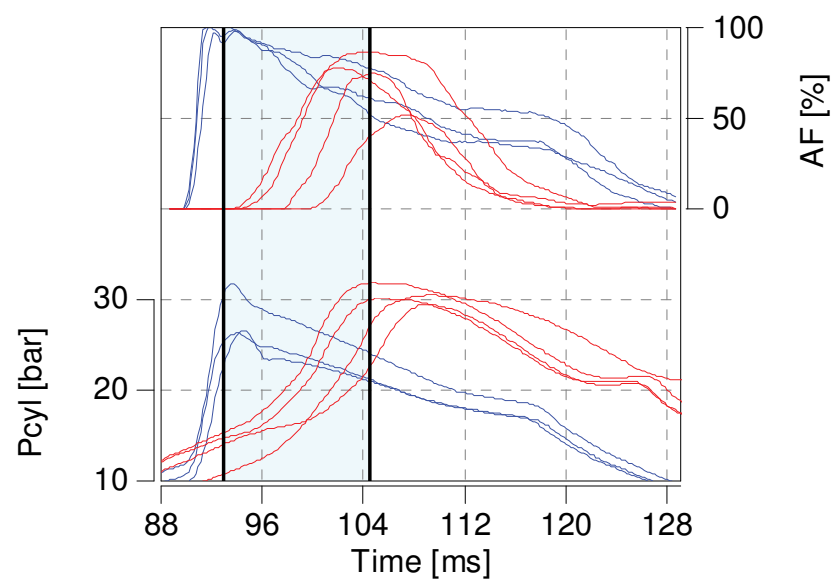

Fig. 7. The flame area in the combustion chamber with marked average times (indicated by black vertical bars) of the recorded maximum values

The supply of non-combustible gases into the combustion chamber resulted in the suppression of growth of both the intensity of the flame and its accumulation in the central part of the cylinder. In this case, the maximum area occupied by the flame reached 50 to $87 \%$ of the viewing window size. This indicates that the research concept has been reached and the flame was isolated from the cylinder walls.

Due to the extensive amount of data obtained in the course of this research further presentation of the results of optical tests in this article is limited to representative individual measuring points. Figure 8 displays the sequences of images of the flame development from the start of the ignition. Since the process was filmed with a frequency of 5 
$\mathrm{kHz}$, the time interval between images was $0.2 \mathrm{~ms}$. In order to present the main features of the whole combustion process the chosen time interval between images shown in Fig. 8 is $2 \mathrm{~ms}$. Comparison of the image timing and indicated test values made it possible to determine the flame image (in pictures) corresponding to the value Pmax for a given measurement point. These pictures are marked with circles.

The analysis of reference measurement images (left) reveals a sharp increase in pressure without the load motion and post-combustion flame around the cylinder walls.
The sequence of images of the combustion measurement in the vicinity of non-combustible gases (Fig. 8; right side) shows the development of the flame in the center of the cylinder. In addition, the flame is suppressed, and in contrast to the reference measurement, no long postcombustion near the cylinder walls was observed. Due to the design of the engine head, where the spark plug is located on the side, a clear swirling of the flames from the ignition point was observed, which corresponded to the turbulence created by the injection of carbon dioxide.
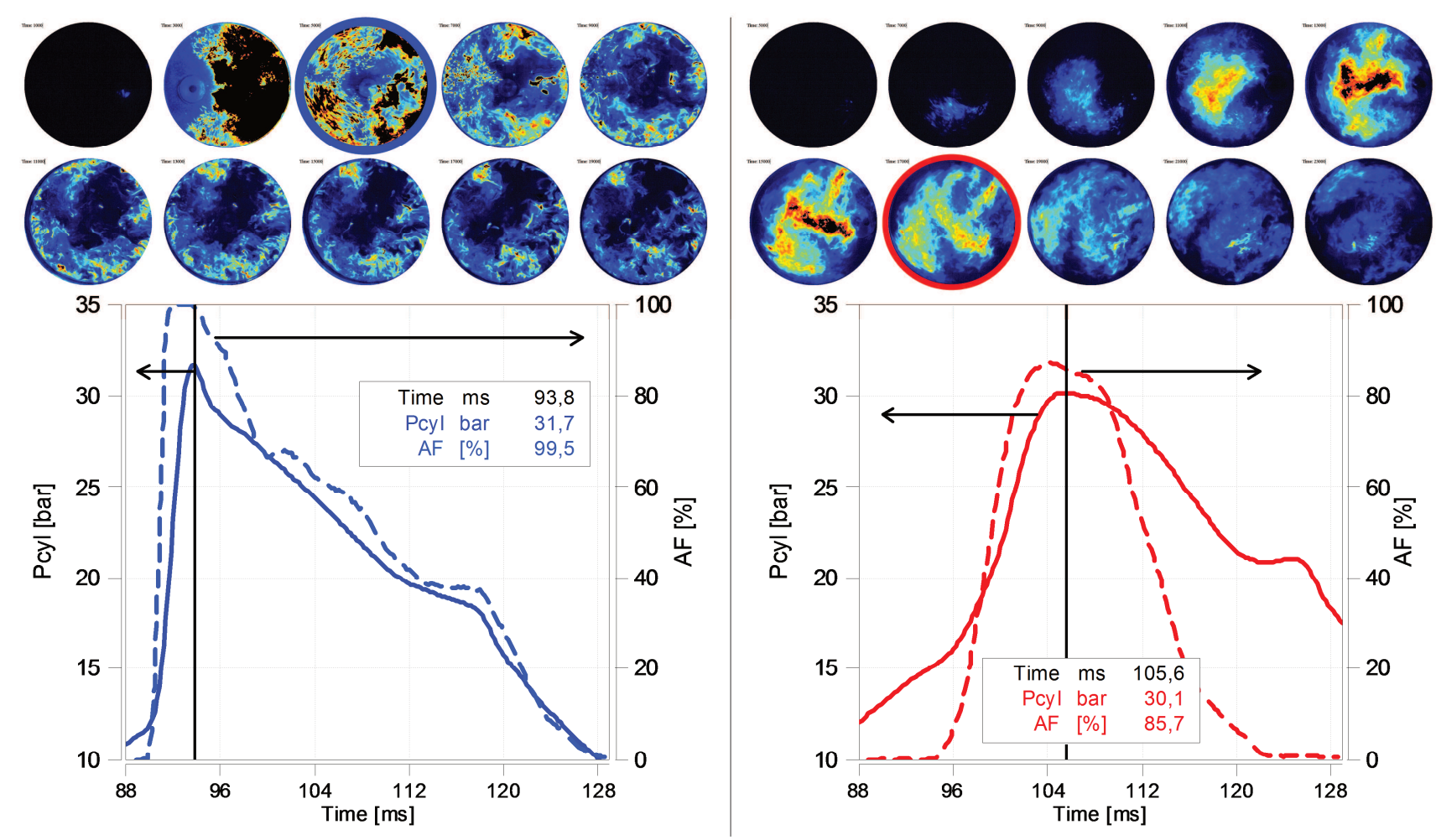

Fig. 8. A comparison of combustion: on the left - a reference measurement, on the right - measurement along with the injection of carbon dioxide

\section{Summary}

The assumed achievement of radial stratification, allowing the separation of the load in the combustion chamber in the spark ignition engine with direct petrol injection has been completed. The test results indicate that the flame access to the cylinder walls was limited. The resulting reduction in flame area ranged from $13 \%$ to $50 \%$ (for the four repeated tests of the combustion process). The proposed system is essential for carrying out further analyzes of the injection sequence effect, and to further develop the concept. In future projects, the Authors expect to use an engine head with a centrally positioned spark plug. This configuration will allow for better flame accumulation inside the cylinder volume.

\section{Acknowledgements}

The study presented in this article was performed within the statutory research.

\section{Nomenclature}

AF area of flame

EGR exhaust gas recirculation

$\mathrm{CO}_{2}$ carbon dioxide

dQ heat release rate
Pcyl cylinder pressure

Pmax maximum cylinder pressure RCM rapid compression machine 


\section{Bibliography}

[1] ALGER, T. Gasoline Engine Technology for High Efficiency, Southwest Research Institute, San Antonio, 2014.

[2] ASAD, U., ZHENG, M. Efficacy of EGR and Boost in Single-Injection Enabled Low Temperature Combustion. SAE International Journal of Engines. 2009, 2(1), 1085-1097.

[3] BOROWSKI, P., CIESLIK, W., PIELECHA, I., WISŁOCKI, K. Evaluation of the repeatability of combustion process in rapid compression machine using optical research. XXII International Symposium on Combustion Processes. 22-25.9.2015, Poland.

[4] CIEŚLIK, W., PIELECHA, I., BOROWSKI, P., WISŁOCKI, K. Evaluation of repeatability of rapid compression machine under selected conditions. ECM 7th - European Combustion Meeting.3-4.4.2015, Budapest.

[5] CIEŚLIK, W., PIELECHA, I., KAPUSTA, Ł. The concept of combustion system with use of recirculated exhaust gas in

Wojciech Cieślik, MEng. - Faculty of Machines and Transport in Poznan University of Technology.

e-mail: Wojciech.Cieslik@put.poznan.pl the spark ignition engine. Combustion Engines. 2015, 162(3), 257-263.

[6] DINGELSTADT, R., EWERT, S., WERZ, M., TREMBLE, P. Potential of exhaust gas recirculation in gasoline engines. MTZ. 2014, 75(9).

[7] HANJALIĆ, K., POPOVAC, M., HADŽIABDIĆ, M. A robust near-wall elliptic-relaxation eddy-viscosity turbulence model for CFD. International Journal of Heat and Fluid Flow. 2004, 25(6) 1047-1051.

[8] PIELECHA, I. Modeling of gasoline fuel spray penetration in SIDI engines. International Journal of Automotive Technology. 2014, 15, 47-55.

[9] TUTAK, W. Possibility to reduce knock combustion by EGR in the SI test engine. Journal of KONES Powertrain and Transport. 2011, 18(3).

[10] WEI, H., ZHU, T., SHU, G., TAN, L., WANG, Y. Gasoline engine exhaust gas recirculation - a review. Applied Energy. 2012, 99, 534-544.

Ireneusz Pielecha, DSc., DEng. - Faculty of Machines and Transport of Poznan University of Technology.

e-mail:Ireneusz.Pielecha@put.poznan.pl 